\title{
A RISK ASSESSMENT MODEL FOR SUPPLY CHAINS
}

\author{
DOI: 10.17261/Pressacademia.2018.866 \\ PAP- V.7-2018(19)-p.122-125
}

Sena Kubra Canbakis ${ }^{1}$, Melike Karabas ${ }^{2}$, Huseyin Selcuk Kilic ${ }^{3}$, Sedef Koseoglư ${ }^{4}$, Ezgi Unal ${ }^{5}$

${ }^{1}$ Marmara University, Goztepe Campus 34722 Kadıkoy, Istanbul, Turkey. senacanbakis@marun.edu.tr, ORCID: 0000-0003-4694-523X

${ }^{2}$ Marmara University, Goztepe Campus 34722 Kadıkoy, Istanbul, Turkey. melikekarabas@marun.edu.tr, ORCID: 0000-0001-5782-0956

${ }_{3}^{3}$ Marmara University, Goztepe Campus 34722 Kadıkoy, Istanbul, Turkey. huseyin.kilic@marmara.edu.tr, ORCID: 0000-0003-3356-0162

${ }^{4}$ Marmara University, Goztepe Campus 34722 Kadıkoy, Istanbul, Turkey. sedefkoseoglu@marun.edu.tr, ORCID: 0000-0001-6641-4458

${ }^{5}$ Marmara University, Goztepe Campus 34722 Kadıkoy, Istanbul, Turkey. ezgiunal@marun.edu.tr, ORCID: 0000-0002-9173-6843

To cite this document

Canbakis, S. K., Karabas, M. K., Kilic, H. S., Koseoglu, S., Unal, E. (2018). A risk assessment model for supply chains. PressAcademia Procedia (PAP), V.7, p.122-125.

Permemant link to this document: $\underline{\text { http://doi.org/10.17261/Pressacademia.2018.866 }}$

Copyright: Published by PressAcademia and limited licenced re-use rights only.

\section{ABSTRACT}

Purpose- This research proposes an integrated methodology to assess the risks in supply chains.

Methodology- Regarding the importance of risk management in supply chains, an integrated model including Failure Mode Effects Analysis (FMEA), Analytic Hierarchy Process (AHP) and Weighted Product (WP) is proposed. Within the proposed methodology, firstly the supply chain risks are determined by both benefiting from the literature and a survey among experts including academics and sector representatives. Afterwards, different from the classical FMEA approach, the three factors; detection, severity and occurrence are weighted via AHP. Then, the supply chain risks are prioritized based on these weighted factors and WP.

Findings- Prioritized sub-risks in supply chain and the most important sub-risk are obtained as a result of the proposed methodology.

Conclusion- The study provides a risk assessment methodology which is an important part of risk management process. It is planned to provide benefit both for the practitioners and academics focusing on risks in supply chains.

Keywords: Risk management, supply chain, FMEA, AHP, WP.

JEL Codes: G32, D81, C44

\section{INTRODUCTION}

Supply chain management serves a function in any organization to perform the business operations successfully. Today's global business environment pushes the businesses to be competitive. In this competitive market, any underestimated risk can affect any business steps and, this situation may cause major loss which depends on the extent of a business. Since that, to estimate the potential failures and to take a precaution before they occur has a vital importance for companies. Risk assessment process can be used to eliminate the loss (Punniyamoorthy et al., 2013).

A supply chain system consists of an integration of supplier, manufacturers, distributors, retailers, and customers. Since it has numerous participants, there are several potential risk sources (Palaniappan, 2014). These risks may be sourced from sudden changes in constraints, failures of quality, miscommunication between business partners or uncontrollable events such as terrorism, earthquake (Diabat et al., 2012). To avoid or mitigate a major loss, it is important to understand and manage the possible risks which were mentioned. Therefore risks should be identified, measured and prioritized and then the proposed method should be developed for mitigation (Aqlan and Lam, 2015).

In the light of this information, the objective of this study is to define the possible risk factors in supply chain steps and assess these risk factors to prioritize them. For this aim an integrated methodology including Failure Mode and Effect Analysis (FMEA), Analytical Hierarchy Process (AHP) and Weighted Product (WP) is utilized. This proposed methodology is applied in a Food and Beverage Company in Turkey.

The remainder of this study is organized as follows: "Section 2" provides the literature review. "Section 3" presents the data and methodology. Findings are given in "Section 4" and finally "Section 5" includes the conclusion with the references following. 


\section{LITERATURE REVIEW}

Risk can be defined as the likelihood of danger, damage, loss, injury or other unintended consequences in general. The Royal Society (1992) provided risk description that the probability of a particular adverse event occurs during a stated period of time. Likewise, risk results from a particular challenge (Palaniappan, 2014). However, risk is also defined as an unclear accident or group of conditions that will affect accomplishment of one or more objectives in compliance with Association of the Project Managers (Tuncel and Alpan, 2010). Supply chain risk assessment process can be mainly classified into three categories: risk identification, risk classification and risk assessment (Palaniappan, 2014)

Risk identification is the first step of risk assessment and one of the critical steps for the success of supply chain management. Risk identification is defined as operation that consists of discovering, determining, defining, documenting and communicating the positional risks which might appear and have an effect on the performance of the supply chain in positive or negative way (Aqlan and Lam, 2015). It helps to improve a general comprehension of uncertainties which might occur in the future, hence noticing the possible risks in order to manage these circumstances adequately (Tuncel and Alpan, 2010). There are many methods to identify risks correctly according to the current circumstances. These methods are: Literature review (Jaberidoost et al., 2015), Qualitative methods (Aqlan and Lam, 2015), Geo mapping/Supply chain mapping, Analyzing historical problems, Researching industry trends, Group of experts brainstorming, Assessment surveys, Site visit (Palaniappan, 2014).

As the second step, risk classification is also important. Selecting and using the most effective techniques for determining the risks of the organization and classifying the identified risks are needed for risk assessment process. After the selection of the risk identification techniques, the identified risks should be classified together with their sources. The classified risks should not overlap with each other as much as possible. The classified risks generate the risk categories in literature as follows: Supply risk, Operation and process risks, Environmental Risk, Regulatory risk (Vilko and Hallikas, 2011), Demand risk, Production risk, Logistics risk (Punniyamoorthy et al., 2013), Customer and market risks, Financial risk (Soni and Kodali, 2013).

Finally, companies try to minimize supply chain risk factors to maximize productivity (Chaudhuri et al., 2013). Palaniappan (2014) explains risks with their likelihoods and impacts. Moreover, to measure the probablity of a risk, an event must occur. The likelihood can not be used to find the frequency of occurrence but historical data make it easier to find probability. Alternatively, the expert's knowledge provides rating scale to calculate probability of risks (Manuj and Mentzer, 2008). Several methods such as Extended Risk Matrix Approach (ERMA) (Li et al., 2013), Cronbach's $\alpha$-value (Punniyamoorthy et al., 2013), FMEA and simulation (Vilko and Hallikas, 2011), A hybrid of fuzzy FMEAAHP(Aslani et al., 2014), combination of FMEA and AHP Approaches (Suebsomran and Talabgeaw, 2013), Interpretive Structural Modelling(ISM) and MICMAC Analysis (Diabat et al., 2012), Influence Diagram (Liu et al., 2009) are applied for risk assessment in the literature.

\section{DATA AND METHODOLOGY}

\subsection{The Proposed Methodology: An Integrated Approach of FMEA, AHP and WP}

In this paper, an integrated approach consisting of FMEA, AHP and WP methods is developed. The proposed model enables to rank the risks according to their importance via calculating New Revised Risk Priority Number (New R-RPN). FMEA is an effective method to prioritize the risks, AHP is an effective Multi Criteria Decision Making (MCDM) tool for setting priorities with calculated weighted values and WP is also a simple MCDM technique that can be used for scoring alternatives.

FMEA: Failure Mode Effect Analysis is a reliable method for failure analysis (Su and Chou, 2008) that is used as a tool for risk assessment (Maheswaran and Loganathan, 2013). Risks are prioritized regarding their Risk Priority Number(RPN) in FMEA and RPN = S(S)* S(O) * S(D) (Maheswaran and Loganathan, 2013), where $S(S)$ is score of severity, $S(O)$ is score of occurrence and S(D) is Score of detection. Severity(S) indicates effect of failure, Occurrence $(O)$ is the frequency of failure, Detection(D) is the probability of detecting the failure and these S, O, D are called as criteria of FMEA. The value of S, O, D is between 1 and 10 according to their importance (Özveri and Kabak, 2016). However, as a deficiency of traditional FMEA, same RPNs might be obtained with different S, O, D values for 2 different failure modes. It stems from assuming that $S, O$, and $D$ have the same importance weights. To eliminate this deficiency, relative importance of $S, O$, $D$ should be taken into account and this relative importance can be calculated with AHP (Aslani et al., 2014).

AHP: In general, AHP is implemented to compute the vector of criteria weights, compute the matrix of option scores, rank the options. However, in this study AHP is used only for computing the vector of criteria weights. To specify the relative importance of criteria, the values between 1 and 9 is used (Su and Chou, 2008). As a result of the AHP, the relative importance of S, O, D is obtained and demonstrated as $W_{(S)}, W_{(O)}, W_{(D)}$ respectively. After obtaining the weights of $S, O, D$ with using AHP, the weighted RPN which called as revised risk priority rumber(R-RPN) can be calculated as:

$R-R P N=W(O) \times S(O)+W(D) \times S(D)+W(S) \times S(S)$, (Hu et al., 2009).

Despite of taking into account the weighted values of S, O, D there is another deficiency in this formulation: this formulation is based on the sum of the weighted values of criterion, contrary of that, formal logic of FMEA is based on product of the values of criterion. Because of that reason, this formulation is not appropriate for logic of FMEA, exactly. To eliminate this deficiency, WP can be used.

WP: Different from the existing literature, an integrated approach of FMEA, AHP and WP is generated to eliminate this defficieny. Multiplication of criteria is necessary to fit the original form of FMEA. So as to make this multiplication valid, the importance weights should be exponentially indicated. At this point WP is considered to be a suitable technique. With using WP, the New Revised Risk Priority Number (New R-RPN) is calculated as: 
New Revised-RPN $=S(O)^{\mathrm{W}(0)} \times S(D)^{\mathrm{W}(D)} \times S(S)^{\mathrm{W}(S)}$, this formulation is the proposed methodology of this study to prioritize the risks according to their New R-RPNs.

\subsection{Data}

Surveys, meeting with managers in case company and literature review are utilized to reach meaningful data in this study. As the first step, a survey which contains the most frequently mentioned risks in the literature was arranged and presented to the academicians and managers in order to specify the categories of risks. After specifying 5 risk categories, the sub-risks of these risk categories were identified via literature review and interviewing with managers. These 5 risk categories and their sub-risks are shown in Table1. In order to apply the proposed methodology to case company, managers evaluated the sub-risks in FMEA survey, and they compared the criteria of FMEA on AHP survey. Thus, S, O, D values for each sub-risk and weighted values of S, O, D (W(S), W (O), W (D)) were obtained. The values of the results of the surveys are demonstrated in Table1. Afterwards, the New R-RPN is calculated for each sub-risk according to New R-RPN formulation. The sub-risks are ranked regarding their New R-RPNs. Highest New R-RPN indicates the most important sub-risk and its rank number is equal to 1 . The New R-RPNs and ranking of the sub-risks are shown in Table 1.

\section{FINDINGS}

After the application of the proposed methodology, the ranks of the sub-risks are obtained. As can be seen in Table 1, "Unanticipated or Volatile Customer Demand" sub-risk is found as the most important risk at supply chain in the case company because it has the highest New R-RPN and for this reason, its rank number is equal to 1 . Similarly, all the other sub-risks are ranked with respect to their New R-RPNs.

Table 1: The New R-RPNs of Risks and Their Ranks

\begin{tabular}{|c|c|c|c|c|c|c|c|c|}
\hline Risks & Occurrence & Wo & Severity & $\mathbf{W}_{\mathrm{s}}$ & Detection & $W_{D}$ & $\begin{array}{l}\text { New } \\
\text { R-RPN }\end{array}$ & Rank \\
\hline \multicolumn{9}{|l|}{ SUPPLY RISKS } \\
\hline Supplier's Inventory & 4 & \multirow{4}{*}{0.314} & 7 & \multirow{4}{*}{0.273} & 9 & \multirow{4}{*}{0.413} & 6,514 & 3 \\
\hline Company's Inventory & 2 & & 8 & & 1 & & 2,193 & 19 \\
\hline Uncapable Supplier & 6 & & 5 & & 7 & & 6,084 & 4 \\
\hline Inconsistent Forecast & 10 & & 5 & & 10 & & 8,276 & 2 \\
\hline \multicolumn{9}{|l|}{ FINANCIAL RISKS } \\
\hline $\begin{array}{l}\text { Uncertainty on Foreign } \\
\text { Exchange Rate }\end{array}$ & 10 & \multirow{4}{*}{0.314} & 10 & \multirow{4}{*}{0.273} & 3 & \multirow{4}{*}{0.413} & 6,082 & 5 \\
\hline The Threat of Economic Crisis & 8 & & 9 & & 3 & & 5,510 & 9 \\
\hline Cyber Risks & 4 & & 8 & & 6 & & 5,714 & 8 \\
\hline $\begin{array}{l}\text { Disagreement on Financial } \\
\text { Aspects with Supplier }\end{array}$ & 5 & & 5 & & 6 & & 5,391 & 10 \\
\hline \multicolumn{9}{|l|}{ OPERATIONAL RISKS } \\
\hline Inconsistent Production Rate & 6 & \multirow{4}{*}{0.314} & 6 & \multirow{4}{*}{0.273} & 2 & \multirow{4}{*}{0.413} & 3,812 & 16 \\
\hline Database Issues within the Company & 7 & & 7 & & 3 & & 4,933 & 12 \\
\hline Mismanaging the Employees & 3 & & 7 & & 3 & & 3,781 & 17 \\
\hline $\begin{array}{l}\text { Inadequate or } \\
\text { Unqualified Employers }\end{array}$ & 3 & & 9 & & 3 & & 4,049 & 15 \\
\hline \multicolumn{9}{|l|}{ DEMAND RISK } \\
\hline $\begin{array}{l}\text { Unanticipated or Volatile Customer } \\
\text { Demand }\end{array}$ & 10 & \multirow{4}{*}{0.314} & 9 & \multirow{4}{*}{0.273} & 10 & \multirow{4}{*}{0.413} & 9,716 & 1 \\
\hline Forecast Errors & 7 & & 3 & & 6 & & 5,212 & 11 \\
\hline Change in Market Trend & 4 & & 5 & & 9 & & 5,942 & 6 \\
\hline Price Strategy & 2 & & 8 & & 1 & & 2,193 & 19 \\
\hline \multicolumn{9}{|l|}{ LOGISTIC RISKS } \\
\hline Inefficiency in Transport Infrastructure & 4 & \multirow{4}{*}{0.314} & 5 & \multirow{4}{*}{0.273} & 3 & \multirow{4}{*}{0.413} & 3,775 & 18 \\
\hline Vehicle Procurement Problem & 7 & & 9 & & 2 & & 4,469 & 14 \\
\hline Track and Trace of Vehicles & 6 & & 7 & & 5 & & 5,804 & 7 \\
\hline Seasonal Logistics & 7 & & 6 & & 3 & & 4,730 & 13 \\
\hline
\end{tabular}




\section{CONCLUSION}

In this paper, a risk assessment model for supply chains is proposed. For this aim, firstly, the supply chain risk factors which have the highest risk rates are investigated via literature review and survey methods. As an output of this part, the most possible five risk factor categories are stated as Supply Risks, Demand Risks, Operational Risks, Financial Risk and Logistic Risks. To specify the sub-risks of these risk categories, data collection tools such as meetings with experts and literature review are utilized.

To assess the determined sub-risks, FMEA is found as the most used and applicable model. But different from the classical FMEA, AHP and WP are also embedded to the classical FMEA for providing a weighted structure. So as to validate the proposed methodology, an application is performed in a company. As a result of the proposed methodology, the most important sub-risk in supply chain is found as "Unanticipated or Volatile Customer Demand". Similarly, the other risks' rankings are also obtained. For further studies, other multi criteria decision making techniques such as Fuzzy AHP, ANP can be utilized and applications in various sectors can be performed. Moreover, comparative analyses can be made between different techniques.

\section{REFERENCES}

Aqlan, F., Lam, S. S. (2015). A fuzzy-based integrated framework for supply chain risk assessment. International Journal of Production Economics, 161, 54-63. doi:10.1016/j.ijpe.2014.11.013

Aslani, R., Feili, H., Javanshir, H. (2014). A hybrid of fuzzy FMEA-AHP to determine factors affecting alternator failure causes. Management Science Letters, 4(9), 1981-1984.

Chaudhuri, A., Mohanty, B. K., Singh, K. N. (2013). Supply chain risk assessment during new product development: a group decision making approach using numeric and linguistic data. International Journal of Production Research, 51(10), 2790-2804.

Diabat, A., Govindan, K., Panicker, V. V. (2012). Supply chain risk management and its mitigation in a food industry. International Journal of Production Research, 50(11), 3039-3050.

Hu, A. H., Hsu, C. W., Kuo, T. C., Wu, W. C. (2009). Risk evaluation of green components to hazardous substance using FMEA and FAHP. Expert Systems with Applications, 36(3), 7142-7147.

Jaberidoost, M., Olfat, L., Hosseini, A., Kebriaeezadeh, A., Abdollahi, M., Alaeddini, M., Dinarvand, R. (2015). Pharmaceutical supply chain risk assessment in Iran using analytic hierarchy process (AHP) and simple additive weighting (SAW) methods. Journal of pharmaceutical policy and practice, $8(1), 9$

Li, Z. P., Yee, Q. M. G., Tan, P. S., Lee, S. G. (2013, December). An extended risk matrix approach for supply chain risk assessment. In Industrial Engineering and Engineering Management (IEEM), 2013 IEEE International Conference on(pp. 1699-1704). IEEE.

Liu, Z., Lai, M., Zhou, T., Zhou, Y. (2009, June). A supply chain risk assessment model based on multistage influence diagram. In Service Systems and Service Management, 2009. ICSSSM'09. 6th International Conference on (pp. 72-75). IEEE.

Maheswaran, K., Loganathan, T. (2013). A novel approach for prioritization of failure modes in FMEA using MCDM. International Journal of Engineering Research and Applications, 3(4), 733-739.

Manuj, I., Mentzer, J. T. (2008). Global supply chain risk management. Journal of business logistics, 29(1), $133-155$.

Özveri, O., Kabak, M. (2016). Çok kriterli karar verme tekniklerinin hata modu ve etkileri analizinde kullanımı. Muğla Sitki Koçman Üniversitesi İktisadi Ve İdari Bilimler Fakültesi Ekonomi Ve Yönetim Araştirmalari Dergisi, 4(2).

Palaniappan, P. K. (2014). Risk assessment and management in supply chain. Global Journal of Research in Engineering, 14(2).

Punniyamoorthy, M., Thamaraiselvan, N., Manikandan, L. (2013). Assessment of supply chain risk: scale development and validation. Benchmarking: An International Journal, 20(1), 79-105.

Soni, G., Kodali, R. (2013). A decision framework for assessment of risk associated with global supply chain. Journal of Modelling in Management, 8(1), 25-53.

Su, C. T., Chou, C. J. (2008). A systematic methodology for the creation of Six Sigma projects: a case study of semiconductor foundry. Expert Systems with Applications, 34(4), 2693-2703.

Suebsomran, A., Talabgeaw, S. (2013). Critical maintenance of thermal power plant using the combination of failure mode effect analysis and AHP approches. King Mongkut's University of Technology North Bangkok International Journal of Applied Science and Technology, 3(3), $1-6$.

Tuncel, G., Alpan, G. (2010). Risk assessment and management for supply chain networks: a case study. Computers in industry, 61(3), 250259.

Vilko, J. P., Hallikas, J. M. (2012). Risk assessment in multimodal supply chains. International Journal of Production Economics, 140(2), 586595 . 